\title{
COMPARAÇÃO DOS ANTICORPOS ANTI-RETICULINA E ANTIENDOMIÍSIO CLASSE IgA PARA DIAGNÓSTICO E CONTROLE DA DIETA NA DOENÇA CELÍACA
}

Lorete Maria da Silva KOTZE* , Shirley Ramos da Rosa UTIYAMA**, Renato Mitsunori NISIHARA**, Valmir MOCELIN**, Roberta Ferreira de Andrade CARVALHO**, Márgara Patrícia Bini ZENI** e Heda Maria Santos AMARANTE***

RESUMO - Sensibilidade ao glúten é um estado de elevada resposta imunológica (celular e humoral) à ingestão de proteínas do glúten do trigo, centeio, cevada e aveia, em indivíduos geneticamente predispostos. A doença celíaca é sua expressão mais freqüente, variando as formas de apresentação. Tem como tratamento a exclusão de alimentos contendo as gliadinas tóxicas. Embora a biopsia do intestino delgado proximal seja necessária, tem-se ressaltado a importância de testes sorológicos no rastreamento, diagnóstico e monitorização da dieta isenta de glúten em pacientes com doença celíaca. O objetivo do presente estudo foi investigar a presença dos anticorpos antiendomísio (EmA-IgA) e anti-reticulina (ARA-IgA) em 56 pacientes celíacos (17 recém diagnosticados; 24 aderentes à dieta; 15 com transgressão à dieta). Os anticorpos foram detectados por imunofluorescência indireta, utilizando como substrato cordão umbilical humano para os EmA-IgA, fígado e rim de rato para os ARA-IgA. Nos pacientes recém diagnosticados e no grupo com transgressão à dieta houve positividade total de 100\% para os EmA-IgA e 59,4\% para ARA-IgA. Nos pacientes aderentes à dieta nenhum dos anticorpos foi detectado. Dentre os 32 pacientes positivos, a concordância foi de 59,4\% (19), sendo que 40,6\% (13/32) eram ARA-IgA negativo e EmA-IgA positivo. Nenhum paciente mostrou-se positivo para os ARA-IgA e negativo para os EmA-IgA. Portanto, a sensibilidade para os EmA-IgA foi de 100\% e de 59,4\% para os ARA-IgA. A associação dos dois testes não aumentou os índices de positividade total nas amostras. Conclui-se que, atualmente, a pesquisa dos EmA-IgA pode constituir teste sorológico de escolha, seja para diagnóstico, seja para seguimento dos pacientes celíacos, pelo alto valor preditivo, alta sensibilidade e especificidade e relativo baixo custo quando se utiliza cordão umbilical humano como substrato.

DESCRITORES - Doença celíaca. Glúten. Anticorpos antiendomísio. Anticorpos anti-reticulina.

* Serviço de Gastroenterologia e Endoscopia Digestiva do Hospital Universitário Cajuru da Pontifícia Universidade Católica do Paraná, Curitiba, PR.

** Laboratório de Imunopatologia, Hospital de Clínicas da Universidade Federal do Paraná, Curitiba, PR.

*** Disciplina de Gastroenterologia, Departamento de Clínica Médica, Universidade Federal do Paraná, Curitiba, PR.

Endereço para correspondência: Dra. Lorete Maria da Silva Kotze - Rua Bruno Filgueira, 369 - Cj. 1205 - 80240-220 - Curitiba, PR. e-mail: loretekotze@hotmail.com 


\section{INTRODUÇÃO}

Sensibilidade ao glúten é um estado de elevada resposta imunológica, tanto celular (células T), como humoral (células B), à ingestão de proteínas do glúten do trigo, centeio, cevada e aveia, em indivíduos geneticamente predispostos. Do ponto de vista clínico, a doença celíaca (DC), expressão mais freqüente desta sensibilidade, pode se apresentar em sua forma clássica com má absorção intestinal, sob formas monossintomáticas, silenciosas ou latentes $^{(11)}$. Ocorre em qualquer idade. Segundo MARSH $^{(25)}$, vários padrões de alterações histológicas podem ser encontrados na mucosa do intestino delgado, desde o chamado tipo pré-infiltrativo, até o de achatamento de vilosidades com hiperplasia de criptas. Outra característica é o aumento no número de linfócitos intra-epiteliais ${ }^{(10,16)}$. Tratamento sob dieta isenta de glúten resulta na recuperação clínica e de mucosa, reduzindo o risco de complicações futuras, tais como redução na fertilidade e linfomas intestinais ${ }^{(18,19)}$.

Até há pouco tempo, o diagnóstico se baseava nos critérios da Sociedade Européia de Gastroenterologia Pediátrica e Nutrição (ESPGAN) ${ }^{(27)}$, dependendo da realização de múltiplas biopsias da mucosa do intestino delgado: uma antes do tratamento, uma na fase de dieta isenta de glúten e outra após o teste com reintrodução do glúten (desafio). Posteriormente, tais critérios foram revi$\operatorname{sados}^{(42)}$. Apesar da biopsia intestinal permanecer como padrão-ouro para o diagnóstico da afecção, nos últimos anos muitos pesquisadores têm procurado testes menos invasivos para diagnóstico, rastreamento e monitorização da dieta.

Os principais marcadores sorológicos descritos são os anticorpos antigliadina (AGA), anticorpos anti-reticulina (ARA) e anticorpos antiendomísio (EmA). Os AGA são investigados usualmente pelo método de ELISA, dosando-se IgG e IgA no soro. Segundo
CHALLACOMBE ${ }^{(8)}$, os anticorpos AGA-IgA mostram-se mais específicos para DC do que os anticorpos AGA-IgG, que demostram maior sensibilidade. Os anticorpos anti-reticulina (ARA-IgA) foram descritos por SEAH et al., em $1971^{(30)}$, sendo detectados através da reação de imunofluorescência indireta, utilizando-se como substrato, estômago, fígado e rim de rato. Representam um teste de triagem sensível e específico para DC não tratada, negativando-se com o tratamento e melhora histológica e retornando a positividade quando o glúten é reintroduzido na dieta. Os anticorpos antiendomísio (EmA-IgA) foram descritos originalmente por CHORZELSKI et al., em $1983^{(9)}$; pertencem à classe IgA e têm como antígeno alvo a substância intermiofibrilar da musculatura lisa do esôfago de macaco. VOLTA et al. ${ }^{(41)}$, usando cordão umbilical humano como substrato, demonstraram a mesma especificidade e sensibilidade para o EmA em ambas as técnicas. Muito recentemente têm sido descritos anticorpos contra transglutaminase tissular (tTG), detectados pelo método ELISA, com sensibilidade e especificidade superponíveis às do EmA-IgA ${ }^{(21,24,33)}$. Os EmA têm mostrado um alto grau de especificidade e sensibilidade nas várias fases da doença, sendo considerado, atualmente, o melhor teste de rastreamento. A sensibilidade e especificidade de todos os testes referidos variam de centro a centro, mas melhoraram com o uso de imunoglobulinas específicas $^{(12)}$.

Antígeno endomisial ocorre em primatas e não em tecidos de roedores, enquanto que o antígeno à reticulina aparece em roedores e não em primatas. Portanto, os anticorpos que surgem podem ser distingüidos pela espécie e órgão-especificidade, concluindo-se que os antígenos reativos com anticorpos endomisiais são distintos dos com reticulina ${ }^{(37)}$. Vários autores têm realizado estudos comparativos entre anticorpos AGA, ARA e EmA tanto para diagnóstico, como para controle da dieta, permitindo melhor avaliação dos índices de sensibilidade e especificidade dos $\operatorname{mesmos}^{(6,32,40)}$.
Os estudos de VASQUEZ et al. ${ }^{(38,39)}$, realizados em familiares assintomáticos de pacientes celíacos, evidenciaram que a associação de dois testes (ARA e EmA) caracterizaram maior sensibilidade na detecção de formas assintomáticas ou latentes da DC. SULKANEN et al. ${ }^{(32)}$ constataram, em pacientes celíacos, que a combinação do EmA, ARA e altos títulos de AGA elevavam os índices de sensibilidade sem prejuízo na especificidade.

TUTHILL et al. ${ }^{(34)}$ demonstraram que a incidência de DC aumentou nitidamente nos últimos três anos com a padronização de vários testes sorológicos, conseguindo-se detectar maior número de casos latentes ou assintomáticos.

No presente estudo, investigou-se a presença dos anticorpos anti-reticulina e antiendomísio em pacientes celíacos recém diagnosticados e pacientes sob tratamento dietético, com o objetivo de comparar a sensibilidade de cada anticorpo investigado, bem como verificar se a associação dos dois testes aumentaria os índices de positividade nos pacientes em estudo.

\section{CASUÍSTICA E MÉTODOS}

\section{Pacientes}

Foram analisadas amostras de soro de 56 pacientes portadores de DC, diagnosticados de acordo com os critérios estabelecidos pela ESPGAN ${ }^{(27)}$ e revisados por WALKER-SMITH et al. ${ }^{(42)}$. Biopsias foram obtidas com cápsulas de Crosby-Kugler ou através de endoscopia digestiva alta ${ }^{(17)}$. O controle do uso de glúten foi realizado através de entrevista clínica com questões relativas à transgressão das recomendações dietéticas, sendo os doentes com ingestão de aproximadamente 3 a $10 \mathrm{~g}$ de glúten por dia considerados "não-aderentes". 
Os pacientes foram divididos em três grupos:

- Grupo 1 - 17 pacientes recém diagnosticados (13 mulheres e 4 homens; faixa de idade 3-66 anos; média de idade: 38 anos);

- Grupo 2 - 24 pacientes aderentes à dieta isenta de glúten (18 mulheres e 6 homens; faixa de idade 5-77 anos; média de idade: 29,4 anos);

- Grupo 3 - 15 pacientes não-aderentes à dieta isenta de glúten (11 mulheres e 4 homens; faixa de idade 9-56 anos; média de idade: 27,3 anos).

\section{Metodologia}

Foram colhidos $10 \mathrm{~mL}$ de sangue de todos os pacientes, sem anticoagulante, sendo o soro separado, aliquotado e armazenado a $-20^{\circ} \mathrm{C}$ até a realização do exame.

\section{Dosagem de IgA total}

A determinação dos níveis séricos totais de IgA circulante foi realizada por turbidimetria, utilizando-se anti-soro específico (Turbiquant/ Behring). As amostras de soro foram diluídas $1: 20$ com solução físiológica $0,85 \%$, sendo a leitura realizada pelo aparelho de turbidimetria (Behring Turbitimer da Behring).

\section{Anticorpos anti-reticulina e anticorpos antiendomísio}

Foram pesquisados através da reação de imunofluorescência indireta, usando-se como substrato cortes criostáticos $(3 \mathrm{~mm})$ de fígado e rim de rato para os ARA, conforme descrito por HÄLLSTRÖM ${ }^{(13)}$; e cordão umbilical humano para os EmA, segundo LADINSER et al. ${ }^{(20)}$. O substrato para os EmA foi fixado na lâmina, utilizando acetona gelada por 10 minutos e clorofórmio por 30 minutos à temperatura ambiente. A seguir, as lâminas foram lavadas três vezes com tampão fosfato salina (PBS), cinco minutos cada vez.

As amostras de soro foram submetidas a uma triagem inicial com diluições em tampão PBS (pH 7,2) 1:2,5, 1:5 e 1:10 tanto para a pesquisa dos ARA, como para os EmA. Estes soros diluídos foram colocados sobre os respectivos cortes e incubados à temperatura ambiente em câmara úmida, por 30 minutos, e lavados com PBS, três vezes, cinco minutos cada vez. A seguir, incubou-se com conjugado fluorescente anti-IgA humano $\mathrm{F}\left(\mathrm{ab}{ }^{\prime}\right)^{2}$ (Kallestad - França) previamente titulado (1:80). As lâminas foram lavadas novamente com PBS e montadas com glicerina alcalina $(\mathrm{pH} 9,5)$. Para cada bateria utilizaram-se soros controles positivos e negativos.

As leituras foram realizadas por dois pesquisadores treinados em microscópio de fluorescência Carl Zeiss, sendo consideradas positivas para os EmA-IgA as amostras que caracterizam fluorescência no tecido de endomísio (substância intermiofibrilar) que contorna as fibras de músculo liso na parede de vasos e artérias do cordão umbilical (Figura 1). Para os ARA-IgA as amostras positivas caracterizaram fluorescência nas fibras ao redor dos glomérulos, túbulos e vasos sangüíneos (rim de rato) (Figura 2) e nas fibras na área portal, contornando os vasos e paredes de sinusóides (fígado de rato). Todos os soros positivos nas diluições iniciais de triagem foram retestados para definição do título final de anticorpos.

\section{RESULTADOS}

A comparação da sensibilidade entre os anticorpos antiendomísio e anti-reticulina na DC pode ser observada na Tabela 1.

Todos os pacientes recém diagnosticados e aqueles com transgressão à dieta isenta de glúten foram positivos para os EmA (100\%), com títulos de anticorpos variando entre 1:2,5 e 1:80. Os anticorpos ARA mostraram-se po-

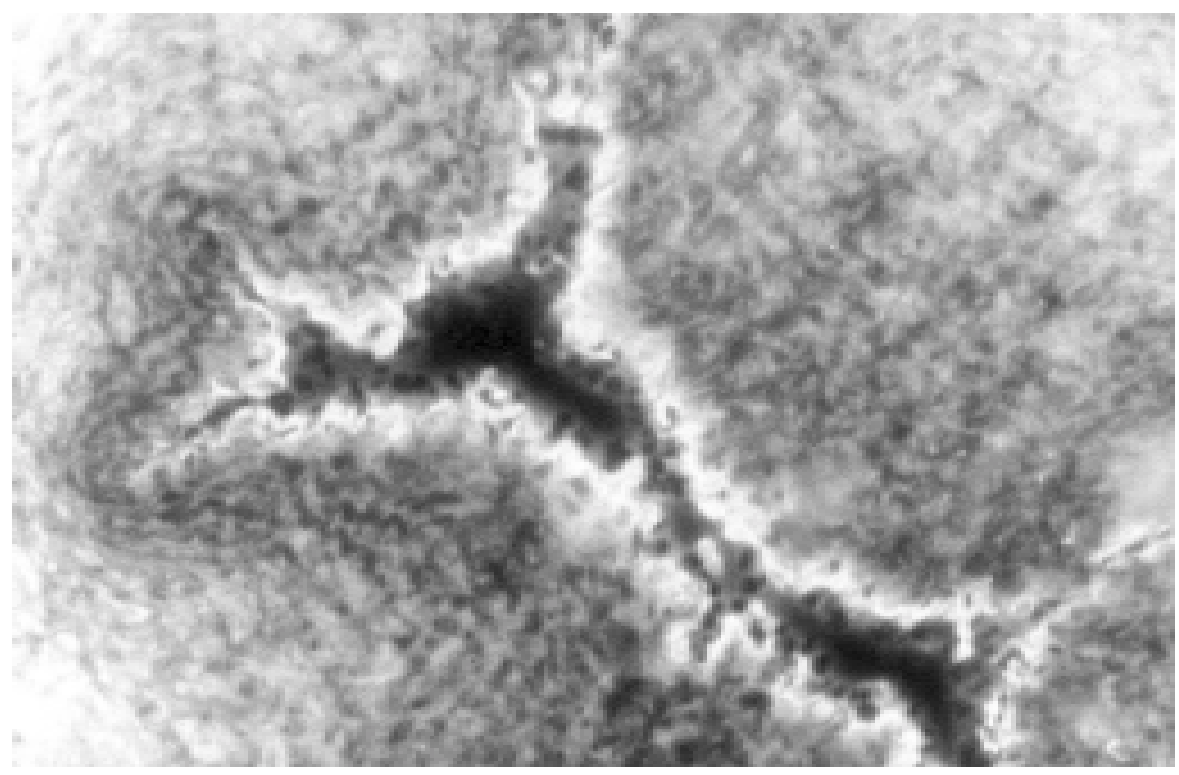

Figura 1 - Anticorpos antiendomísio (EmA-IgA): padrão fluorescente em substância intermiofibrilar de cordão umbilical humano que contorna as fibras do músculo liso na parede de vasos e artérias (aumento $400 \mathrm{X}$ ). 


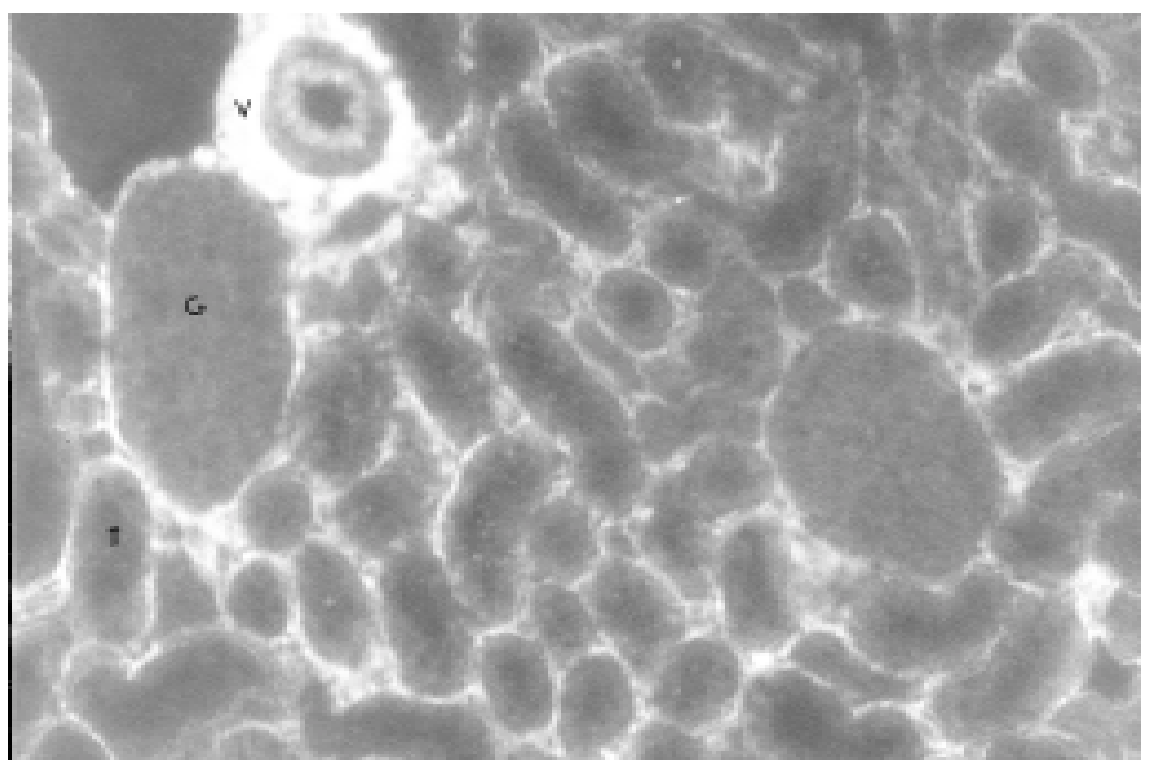

Figura 2 - Anticorpos anti-reticulina (ARA-IgA): padrão fluorescente nas fibras ao redor dos glomérulos $(\mathrm{G})$, túbulos renais $(\mathrm{T})$ e vasos sangüíneos $(\mathrm{V})$ em rim de rato (aumento $400 \mathrm{X}$ ).

Tabela 1 - Positividade para os anticorpos antiendomísio (EmA-IgA) e anti-reticulina (ARA-IgA) na DC

\begin{tabular}{lccc}
\hline Grupo & n & Ema-IgA & ARA-IgA \\
\hline Pacientes recém diagnosticados & 17 & $100 \%(17 / 17)$ & $64.7 \%(11 / 17)$ \\
Pacientes aderentes à dieta & 24 & $0 \%(0 / 24)$ & $0 \%(0 / 24)$ \\
Pacientes com transgressão à dieta & 15 & $100 \%(15 / 15)$ & $53.3 \%(8 / 15)$ \\
Total & 56 & Positivos: 32 & Positivos:19 \\
& & Negativos: 24 & Negativos:37 \\
\hline
\end{tabular}

Sensibilidade EmA-IgA: $100 \%$

Sensibilidade ARA-IgA: $59.4 \%$

sitivos em 11 pacientes recém diagnosticados $(64,7 \%)$ e em 8 pacientes em uso de glúten $(53,3 \%)$, com uma variação de títulos entre 1:10 e 1:80, como se verifica na Figura 3.

Nos pacientes aderentes à dieta de glúten, não foi detectada positividade para nenhum dos anticorpos investigados $(0 \%)$.

Observou-se que no total de 32 pacientes positivos, a concordância de positividade entre os EmA e ARA foi de 59,4\% (19/32), sendo que 40,6\% (13/32) eram ARA negativo e EmA positivo. Nenhum paciente mostrouse positivo para os ARA e negativo para os EmA. Todas as amostras positivas para os
EmA e negativas para os ARA apresentavam baixos títulos (1:2,5 a 1:10) como caracteriza a Figura 4.

Em relação aos títulos obtidos nas amostras positivas tanto para os ARA, como para os EmA (19/32), cinco apresentavam os mesmos títulos, quatro tinham títulos superiores para os EmA e 10 tinham títulos superiores para os ARA (Figura 4).

A análise final dos dados permitiu caracterizar sensibilidade de $100 \%$ para os EmA e de 59,4\% para os ARA. A associação dos dois testes não aumentou estes índices nas amostras em estudo.

\section{DISCUSSÃO}

Desde a descoberta de CHORZELSKI et al., em $1983^{(9)}$, caracterizando a presença dos anticorpos antiendomísio, classe IgA (EmA-IgA) no soro de pacientes com DC, inúmeros estudos têm evidenciado, de forma crescente, a aplicabilidade deste teste na seleção de pacientes para biopsias do intestino delgado, bem como no rastreamento, diagnóstico e controle da dieta na $\mathrm{DC}^{(23,28,40,41)}$.

Embora se disponha na literatura nacional de vários estudos e revisões relacionados a aspectos clínicos, histológicos e de controle da $\operatorname{dieta}^{(18,19,35)}$, observa-se que as abordagens sorológicas são restritas ou limitam-se, às vezes, à investigação de um único tipo de anticorpo $^{(29)}$. Este fato, certamente, está relacionado tanto ao alto custo dos "kits", quando se pretende investigar os anticorpos antigliadina por ELISA (AGA-IgA e AGAIgG), assim como a dificuldades de infraestrutura para congelamento e cortes criostáticos dos tecidos, quando se quer investigar os anticorpos EmA e ARA por imunofluorescência indireta.

Cabe ainda enfatizar a pouca probabilidade de se obter um número considerável de pacientes em algumas regiões do País, onde a própria origem étnica da população não é a que mais caracteriza os pacientes celíacos.

Neste estudo foram investigados os anticorpos EmA e ARA simultaneamente em 56 amostras de soros de portadores de DC. A Tabela 1 deixa evidente a maior sensibilidade dos EmA-IgA nos pacientes recém diagnosticados $(100 \%)$ e naqueles com transgressão à dieta $(100 \%)$, quando comparado aos ARAIgA $(64,7 \%$ e 53,3\%, respectivamente). Em relação aos EmA-IgA, tais resultados são compatíveis com os de diversos autores, como se verifica na Tabela 2, em que predomina alta sensibilidade para os EmA-IgA, embora alguns estudos, como os de BOIGE et al. ${ }^{(3)} \mathrm{e}$ 


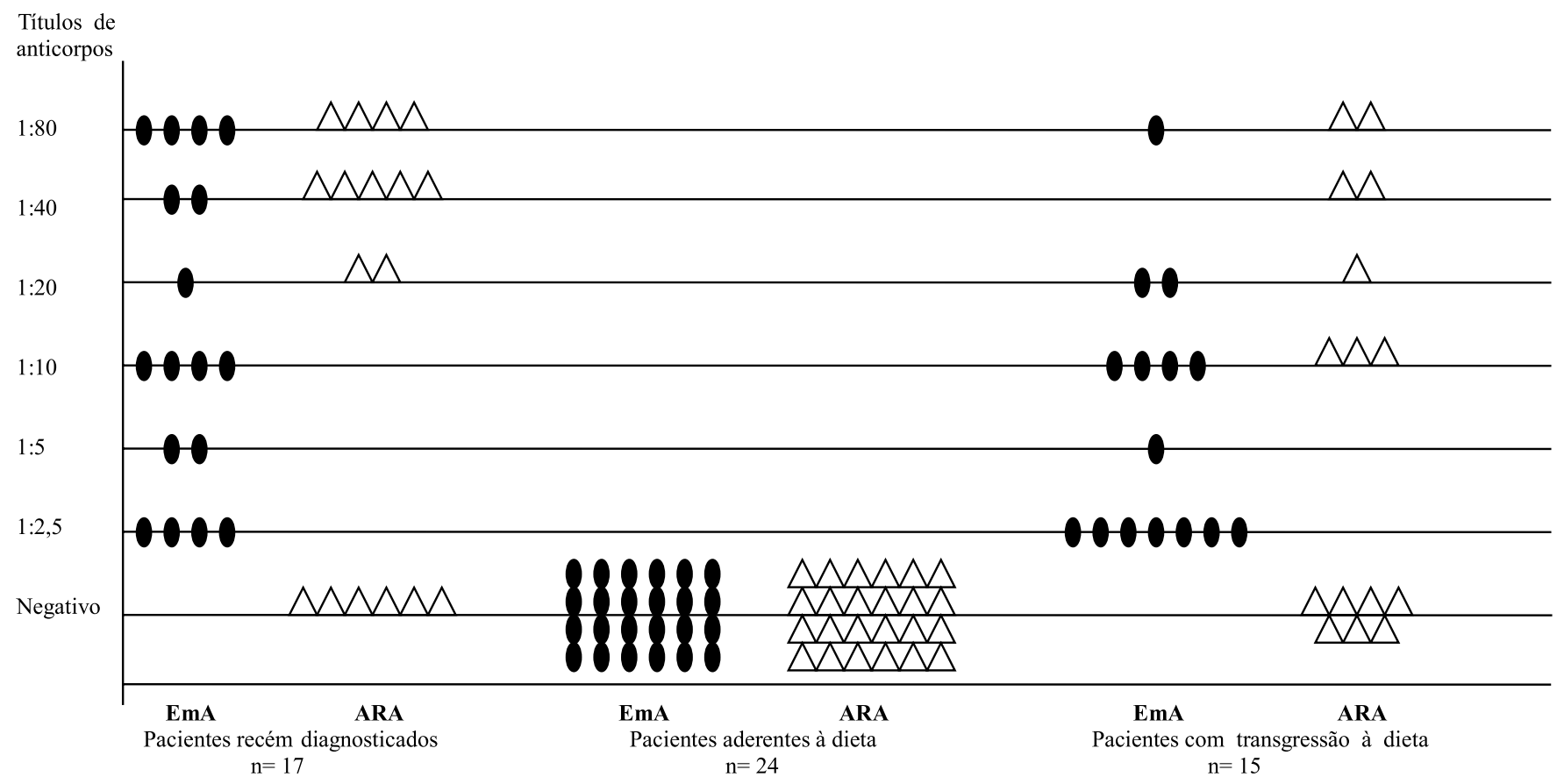

Figura 3 - Distribuição de títulos dos anticorpos EmA-IgA e ARA-IgA

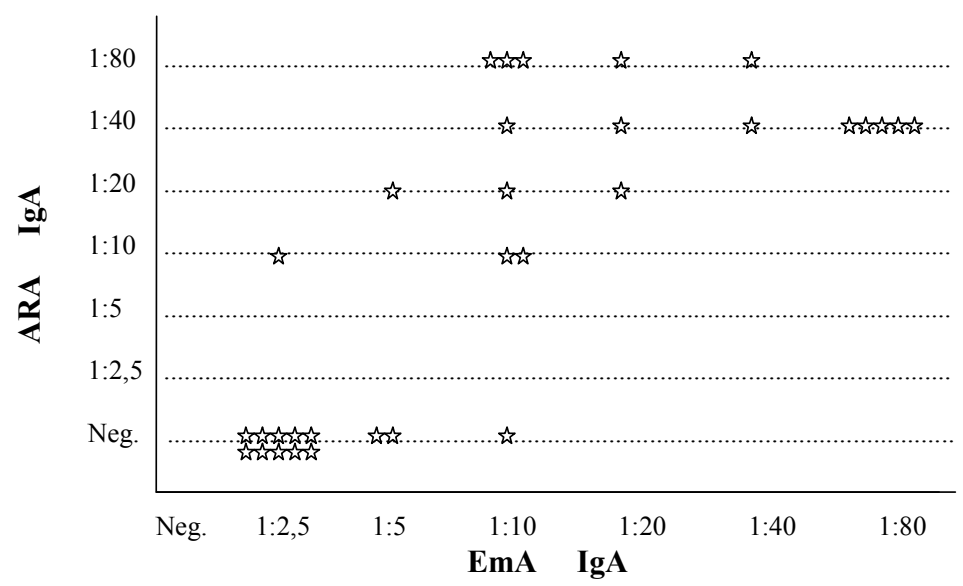

Figura 4 - Correlação de títulos entre ARA-IgA e EmA-IgA

SULKANEM et al. ${ }^{(32)}$ apresentem valores de $88 \%$ e de $85 \%$, respectivamente. Para os anticorpos ARA, os relatos mostram grande diversidade de resultados, com uma sensibilidade variando de 50\% a 92\% (Tabela 2). De acordo com HÄLLSTRÖM ${ }^{(13)}$, esta diferença pode estar relacionada ao fato de que alguns autores utilizaram apenas um substrato para a pesquisa dos ARA, enquanto outros usaram blocos compostos de dois ou mais tecidos.
No presente estudo empregou-se rim e fígado de rato simultaneamente na pesquisa dos ARA e, ainda assim, a sensibilidade alcançada foi de $59,4 \%$. Tais resultados sugerem outros fatores, além do número de tecidos usados como substrato, influenciando nos resultados. É inquestionável a elevada sensibilidade dos $\mathrm{EmA}^{(6,8,41)}$ e alguns trabalhos evidenciam que aspectos envolvendo o antígeno alvo no tecido e a espécie especificidade dos anticorpos detectados nos dois métodos possam explicar os índices de positividade superiores dos EmA em relação aos $\operatorname{ARA}^{(13,37)}$.

SEAH et al. ${ }^{(31)}$ obtiveram $85 \%$ de positividade para os ARA em crianças celíacas com dieta normal e 29\% naquelas com restrição ao glúten. No grupo de adultos, os valores foram de $60 \%$ e $16 \%$, respectivamente. Os autores tentam explicar o fato destes anticorpos não serem detectados no soro de todos os pacientes não tratados, sugerindo uma ligação total dos mesmos aos tecidos (in vivo), assim como colocam em dúvida a restrição total ao glúten naquelas crianças e adultos em tratamento e com reações ARA positivas ( $29 \%$ e $16 \%$, respectivamente). Outros autores reforçam tais questionamentos, enfatizando a importância dos testes sorológicos na monitorização da dieta como um alerta ao paciente e ao clínico e chamam a atenção para o tempo de restrição ao glúten e a negativação dos testes ${ }^{(5,14)}$. Neste estudo, os pacientes aderentes à dieta com ausência total de EmA e ARA (0\%), encontravam-se 
Tabela 2 - Sensibilidade dos anticorpos anti-reticulina (ARA-IgA) e antiendomísio (EmAIgA) em pacientes celíacos adultos, por diferentes autores de vários países

\begin{tabular}{lclcc}
\hline Autor & Ano & País & $\begin{array}{c}\text { ARA-IgA } \\
\text { Sensibilidade }\end{array}$ & $\begin{array}{c}\text { EmA-IgA } \\
\text { Sensibilidade }\end{array}$ \\
\hline Hällström & 1989 & Finlândia & $91 \%$ & $91 \%$ \\
Mäki et al. & 1991 & Finlândia & $92 \%$ & $92 \%$ \\
Ferreira et al. & 1992 & Inglaterra & $90 \%$ & $100 \%$ \\
Mascart-Lemone et al. & 1992 & Bélgica & $62 \%$ & $100 \%$ \\
Boige et al. & 1996 & França & $50 \%$ & $88 \%$ \\
Korponay-Szabó et al. & 1996 & Hungria & $98,8 \%$ & $100 \%$ \\
Sulkanem et al. & 1998 & Finlândia & $78 \%$ & $85 \%$ \\
Kotze et al. & 1999 & Brasil & $59,4 \%$ & $100 \%$ \\
\hline
\end{tabular}

em restrição ao glúten há mais de um ano, atingindo, em alguns casos, até 30 anos de dieta isenta de glúten.

Nas amostras analisadas no presente trabalho, predominaram pacientes do sexo feminino, como se verifica em relatos de outros autores $^{(6,36)}$. A idade variou de 3 a 77 anos, sendo que a idade média dos recém diagnosticados (38 anos) foi superior a dos outros grupos (grupo $2=29,4$ anos e grupo $3=27,3$ anos). Chama a atenção o fato de se ter diagnosticado DC até em paciente de 66 anos, demonstrando que tal afecção pode ocorrer em qualquer idade e que o diagnóstico pode ser tardio.

Ressalta-se que não foram incluídas neste estudo comparativo entre os EmA e ARA, crianças com idade inferior a 3 anos, pois se considera sensibilidade maior dos EmA após o segundo ano de vida. Os estudos de ASCHER et al..$^{(1)}$ evidenciam alta sensibilidade e especificidade para os AGA em crianças com menos de 5 anos de idade, enquanto em crianças mais velhas e adultos, os EmA mostraram-se significativamente melhores. KORPONAYSZABÓ et al. ${ }^{(15)}$ reforçam o decréscimo da sensibilidade dos AGA com o aumento da idade. Estes aspectos, bem como a baixa especificidade dos AGA em DC de adultos, fizeram com que a determinação dos mesmos não fosse realizada no presente estudo, comparativamente aos ARA e EmA.
BURGIN-WOLFF et al. ${ }^{(4)}$ afirmam que praticamente todos os indivíduos com intolerância persistente ao glúten produzem anticorpos em algum momento, com uma ampla variação individual relacionada ao tempo, tipo e quantidade de anticorpo produzido. Este estudo reforça tais afirmações. A Figura 3 permite observar os anticorpos ARA e EmA em todas as amostras analisadas, ficando nítida a diferença de sensibilidade obtida entre os dois métodos, bem como a variação de títulos dos anticorpos detectados. Enquanto para os EmA a variação foi de 1:2,5 a 1:80, tanto nos pacientes recém diagnosticados, como naqueles com transgressão à dieta, observou-se que para os ARA a variação foi de 1:20 a 1:80 e 1:10 a 1:80, respectivamente. Outros autores mostram resultados semelhantes ${ }^{(28,39)}$. Tanto os EmA como os ARA não foram detectados nos pacientes aderentes à dieta.

Por outro lado, a Figura 4 mostra aspectos interessantes em relação aos títulos de anticorpos nas amostras positivas simultaneamente para os ARA e EmA (19/32). Em apenas cinco amostras obteve-se igualdade nos títulos (26,3\%); em quatro destas, os títulos dos EmA eram superiores aos ARA (21\%) e 10 tinham títulos de ARA superiores aos EmA (52,6\%). Chama a atenção que todas as amostras positivas para os EmA e negativas para os ARA (13/32) apresentavam baixos títulos (1:2,5 a 1:10), ficando evidente a maior sensibilidade dos EmA na detecção de baixos níveis de anticorpos. Como nenhum paciente apresentou-se positivo para os ARA e negativo para os EmA, verifica-se que a associação dos dois testes não aumentou a positividade total das amostras, como foi observado por SULKANEN et al. ${ }^{(32)}$ ao associar EmA, ARA e AGA, bem como por VASQUEZ et al. ${ }^{(39)}$ ao associar EmA e ARA.

Embora a deficiência de IgA seja aproximadamente 10 vezes mais comum em pessoas com DC do que na população geral, nenhum paciente apresentou tal condição neste estudo, não tendo sido necessária a investigação dos EmA-IgG nestas amostras, como recomendado por vários autores $^{(2,32)}$. Embora CATALDO et al. ${ }^{(7)}$ recomendem uma avaliação de rotina para deficiência de IgA em laboratórios que fazem sorologia para DC, LOCK e UNSWORTH(22) consideram tal conduta excessiva, sugerindo fazê-lo apenas nos casos com altos níveis de AGA-IgG e EmA-IgA negativo.

Analisando de forma global, os resultados do presente estudo reforçam a aplicabilidade dos anticorpos antiendomísio e anti-reticulina na detecção de enteropatias por sensibilidade ao glúten e no controle da dieta em pacientes celíacos. A elevada sensibilidade dos EmA (100\%) em relação aos ARA $(59,4 \%)$ vem ao encontro de relatos de diferentes autores e, aliado ao fato que a associação dos dois testes não elevou os índices de positividade nas amostras, do ponto de vista econômico julgase dispensável o uso rotineiro da determinação dos ARA.

Pode-se sugerir, em concordância com outros autores que, atualmente, a pesquisa dos anticorpos antiendomísio representa o teste sorológico de escolha tanto para o diagnóstico da DC, como para o controle da dieta, considerando sua alta especificidade e sensibilidade, reforçado pelo grande valor preditivo e baixo custo quando se utiliza cordão umbilical humano como substrato. 
Kotze LM da S, Utiyama SR da R, Nisihara RM, Mocelin V, Carvalho RF de A, Zeni MPB, Amarante HMS. Comparison of IgA class reticulin and endomysium antibodies for diagnosis and control of the diet in celiac disease. Arq Gastroenterol, São Paulo, 36(4):177-184, 1999.

ABSTRACT - Sensibility to gluten is a condition with high immunological reaction against gluten proteins from wheat, barley, rye and oats in individuals genetically susceptible. Celiac disease is its most frequent expression with various forms of clinical presentation. The treatment consists in gluten free diet. Although the biopsy of proximal small bowel is necessary, the importance of serological tests is increasing in the screening, diagnosis and monitoring of gluten free diet in celiac patients. The aim of this study was to investigate the presence of antiendomysium (EmA-IgA) and anti-reticulin (ARA-IgA) antibodies in 56 celiac patients (17 at diagnosis, 24 adherent to the diet and 15 with transgression to the diet). The antibodies were detected by indirect immunofluorescence, using human umbilical cord as substrate for the EmA-IgA and rat liver and kidney for the ARA-IgA. In the patients at diagnosis and in the group with transgression to the diet the total positivity was 100\% for EmA-IgA and 59.4\% for ARA-IgA. Antibodies were not detected in gluten-free diet patients. Among the 32 positive patients, the concordance of both tests was of 59.4\% (19/32), being 40,6\% (13/ 32) negative to ARA-IgA and positive to EmA-IgA. No patient was positive for ARA-IgA and negative for EmA-IgA. Thus, the sensitivity for EmA-IgA was of 100\% and 59,4\% for ARA-IgA. The association of the two tests did not improve the positivity in the samples. In conclusion, EmA-IgA can be considered the best serological test for diagnosis and follow up of celiac patients, because it presents high predictive value, high specificity and sensibility and is not expensive if using human umbilical cord as substrate.

HEADINGS - Celiac disease. Gluten. Antiendomysium antibodies. Antireticulin antibodies.

\section{REFERÊNCIAS BIBLIOGRÁFICAS}

1. Ascher H, Hahn-Zoric M, Hanson LA, Kilander AF, Nilsson LA, Tlaskalova H. Value of serologic markers for clinical diagnosis and population studies of coeliac disease. Scand J Gastroenterol, 31:61, 1996.

2. Beutner EH, Kumar V, Chorzelski TP, Szaflarska-Czerwionka M. IgG endomysial antibodies in IgA-deficient patient with coeliac disease. Lancet, 1:1261, 1989.

3. Boige V, Bouhnik Y, Delchier JC, Jian R, Matuchansky C, Andre C. Antiendomysium and anti-reticulin antibodies in adults with celiac disease followed-up in the Paris area. Gastroenterol Clin Biol, 20:931, 1996.

4. Burgin-Wolff A, Gaze H, Hadziselimovic F, Huber H, Lentze MJ, Reymond-Berthet C. Antigliadin and antiendomysium antibody determination for coeliac disease. Arch Dis Child, 66:941, 1991.

5. Calabuig M, Torregosa R, Polo P, Tuset L, Tomás C, Alvarez V, Garcia-Vila A, Brines J, Vilar P, Farré C, Varca V. Serological markers and celiac disease: a new diagnostic approach? J Pediatr Gastroenterol Nutr, 10:435, 1990.

6. Cataldo F, Ventura A, Lazzari R, Balli F, Nassinbeni G, Marino V. Antiendomysium antibodies and coeliac disease: solved and unsolved questions. An Italian multicentre study. Acta Paediatr, 84:1125, 1995.

7. Cataldo F, Marino V, Bottaro G, Greco P, Ventura A. Celiac disease and selective immunoglobulin A deficiency. J Pediatr, 131:306, 1997.
8. Challacombe DN. Screening tests for coeliac disease. Arch Dis Child, 73:3, 1995.

9. Chorzelski TP, Sulej J, Tchorzewska H, Jablonska S, Beutner EH, Kumar $\mathrm{V}$. IgA class endomysium antibodies in dermatitis herpetiformis and celiac disease. Ann NY Acad Sci, 420:325, 1983.

10. Ferguson A, Murray D. Quantitation of intraepithelial lymphocytes in human jejunum. Gut, 12:988, 1971.

11. Ferguson A. New perspectives of the pathogenesis of coeliac disease: evolution of a working clinical definition. J Int Med, 240:315, 1996.

12. Ferreira M, Davies SL, Butler M, Scott D, Clark M, Kumar P. Endomysial antibody: is it the best screening test for coeliac disease? Gut, 33:1633, 1992.

13. Hällström O. Comparison of IgA-class reticulin and endomysium antibodies in celiac disease and dermatitis herpetiformis. Gut, 30:1225, 1989 .

14. Kapuscinska A, Zalewski T, Chorzelski TP, Sulej J, Beutner EH, Kumar V, Rossi T. Disease specificity and dynamics of changes in IgA class anti-endomysial antibodies in celiac disease. J Pediatr Gastroenterol Nutr, 6:529, 1987.

15. Korponay-Szabó IR, Kovacs JB, Czinner A, Goracz G, Vamos A, Szabo T. High prevalence of silent celiac disease in preschool children screened with $\mathrm{IgA} / \mathrm{IgG}$ antiendomysium antibodies. J Pediatr Gastroenterol Nutr, 28:23, 1999. 
16. Kotze LMS. Padrões histológicos e linfócitos intra-epiteliais da mucosa do intestino delgado nas diarréias crônicas. Curitiba, 1988. [Dissertação de Mestrado - Universidade Federal do Paraná].

17. Kotze LMS. Receitas para pessoas com sensibilidade ao glúten. Rio de Janeiro, Revinter, 1996. p. 160.

18. Kotze LMS. Distúrbios entéricos da absorção. In, Dani R, ed. Gastroenterologia essencial. Rio de Janeiro, Guanabara Koogan, 1998. p. 211-34.

19. Kotze LMS, Pisani JC. Endoscopia e biopsia per oral do intestino delgado. In: Kotze LMS. Diarréias crônicas. Diagnóstico e tratamento. Rio de Janeiro, Medsi, 1992. p. 85-112.

20. Ladinser B, Rossipal E, Pittscheier K. Endomysium antibodies in coeliac disease: an improved method. Gut, 35:776, 1994.

21. Lock RJ, Unswoth DJ. Identifying immunoglobulin-A-deficient children and adults does not necessarily help the serologic diagnosis of coeliac disease. J Pediatr Gastroenterol Nutr, 28:81, 1999.

22. Lock RJ, Gilmour JE, Unsworth DJ. Anti-tissue transglutaminase, anti-endomysium and anti-R1-reticulin autoantibodies the antibody trinity of coeliac disease. Clin Exp Immunol, 116:258, 1999.

23. Mäki M, Holm K, Lipsanen V, Hällström O, Viander M, Collin P, Savilahti E, Koskimies S. Serological markers and HLA genes among healthy first degree relatives of patients with coeliac disease. Lancet, 338:1350, 1991.

24. Mäki M. Autoantibodies and autoantigens in coeliac disease. In: International Symposium on Coeliac Disease, 8., Castel Sant'Elmo, Naples Italy, 1999. p.31.

25. Marsh MN. Mucosal pathology in gluten sensitivity. In: Marsh MN. Coeliac disease. Oxford, Blakwell Scientific Publications, 1992. p. 136-91.

26. Mascart-Lemone F, Van den Broeck J, Cadranel S, Colombel JF. Serological aspects of coeliac disease. Acta Gastroenterol Belg, 55:200, 1992.

27. Meuwisse GW. Diagnostic criteria in coeliac disease. Acta Pediatr Scand, 59:461 1970.

28. Patcht A, Sinai N, Hornstein L, Kumar V, Ish-Shalom N, Lerner, A. The diagnostic reliability of anti-endomysial antibody in celiac disease: the north Israel experience. Israel J Med Sci, 31:218, 1995.

29. Romaldini CC, Barbieri D. Estudo do anticorpo sérico antigliadina da classe imunoglobulina A na doença celíaca. Arq Gastroenterol, 34:254, 1997.
30. Seah PP, Fry L, Hoffbrand AV, Holborow EJ. Tissue antibodies in dermatitis herpertiformis and adult coeliac disease. Lancet, 1:834, 1971.

31. Seah PP, Fry L, Holborow EJ, Rossiter MA, Doe WF, Magalhães AF, Hoffbrand AV. Antireticulin antibody: incidence and diagnostic significance. Gut, 14:311, 1973.

32. Sulkanen S, Collin P, Laurila K, Maki M. IgA- and IgG- class antihuman umbilical cord antibody tests in adult coeliac disease. Scand J Gastroenterol, 33:251, 1998.

33. Sulkanen S, Halttunen T, Laurila K. Tissue transglutaminase autoantibody enzyme-linked immunosorbent assay in detecting celiac disease. Gastroenterology, 115:1322, 1998.

34. Tuthill DP, Hawkes N, Fifield R, Williams P, Jenkins HR. The rise of childhood coeliac disease following antibody testing introduction. In: International Symposium on Coeliac Disease, 8., Castel Sant'Elmo, Naples, Italy, 1999. p.220.

35. Utiyama SRR, Ioshii S. Doença celíaca: uma visão atual. Rev Bras Anál Clín, 30:151, 1998.

36. Valdimarsson T, Franzen L, Grodzinsky E, Skogh T, Ström M. Is small bowel biopsy necessary in adults with suspected celiac disease and IgA anti-endomysium antibodies? Dig Dis Sci, 41:83, 1996.

37. Valeski JE, Kumar V, Beutner EH, Lerner A, Chorzelski TP. Immunology of celiac disease: tissue and species especificity of endomisial and reticulin antibodies. Int Arch Allergy Appl Immunol, 93:1, 1990.

38. Vasquez H, Sugai E, Pedreira S, Katz S, Litwin N, De Rosa S, Ruiz J. Screening for asymptomatic celiac sprue in families. J Clin Gastroenterol, 21:130, 1995.

39. Vasquez H, Cabanne A, Sugai E, Fiorini A, Pedreira S, Maurino E, Smecuol E, Dezi R, Niveloni S, Valero J, De Rosa S, Litwin N, Kogan Z, Boerr LA, Bai JC. Serological markers identify histologically latent coeliac disease among first-degree relatives. Eur J Gastroenterol Hepatol, 8:15, 1996.

40. Vogelsang H, Genser D, Wyatt J, Lochs H, Ferenci P, Granditsch G, Penner E. Screening for celiac disease: a prospective study on the value of noninvasive tests. Am J Gastroenterol, 90:394, 1995.

41. Volta U, Molinaro N, Franceschi L, Fratangelo D, Bianch FB. IgA anti-endomysial antibodies on human umbilical cord tissue for celiac disease screening. Dig Dis Sci, 40:1902, 1995.

42. Walker-Smith JA, Guandalini S, Schimitz J, Schmerling DH, Viscorpi JK. Revised criteria for diagnosis of coeliac disease. Arch Dis Child, 65:909, 1990. 